\title{
Comparative LCA of Two Thermal Energy Storage Systems for Shams1 Concentrated Solar Power Plant: Molten Salt vs. Concrete
}

\author{
Jubilee T. Adeoye, Yamrot M. Amha, Vahan H. Poghosyan, Khachatur Torchyan, and Hassan A. Arafat
}

\begin{abstract}
Thermal energy storage (TES) for concentrated solar power (CSP) is gaining popularity because it has the potential to increase the hours of electricity production from the CSP technology. In this Study, we conducted a comparative life cycle assessment (LCA) of two TES technologies (concrete and molten salt) for Shams-1 CSP plant in United Arab Emirates. Eco-Indicator 99 was employed to model the environmental impact per 800MWhe produced. Results obtained show that concrete TES has a greater environmental impact than molten salt TES, with fossil fuel being the largest impact contributor in both cases. A sensitivity analysis in which different scenarios were considered showed a reduction in environmental impact when waste recycling and transportation changes are incorporated. Based on the results obtained, incorporating molten salt TES in Shams 1 will have a lower environmental impact than the use of concrete TES.
\end{abstract}

Index Terms-Concentrated solar power plant, concrete storage, life cycle assessment, molten salt storage, thermal energy storage.

\section{INTRODUCTION}

Since the beginning of the industrial revolution, the atmospheric concentration of carbon dioxide has increased alarmingly by about $30 \%$, due to human activities such as combustion of fossil fuels [1]. In Australia for example, electricity generation accounts for $45 \%$ of the carbon dioxide emission [2]. There is a need to reduce the quantity of $\mathrm{CO}_{2}$ emission in order to mitigate its global warming effect. Hence, the development of renewable sources of electricity becomes relevant as the global requirement for electricity increases.

Electricity generation using Concentrated Solar Power (CSP) is a relatively new technology that utilizes solar thermal energy to produce electricity. In this system, highly reflective mirrors are employed to concentrate the Direct Normal Irradiance (DNI) of sunlight on receivers, through which Heat Transfer Fluid (HTF) is pumped. Afterwards, the HTF transfers the acquired heat to a steam generator to

Manuscript received June 10, 2013; revised July 29, 2013.

J. T. Adeoye, Y. M. Amha, and H. A. Arafat are with the water and environmental engineering program, Masdar Institute of Science and Technology, Abu Dhabi, 54224 UAE (e-mail: jadeoye@Masdar.ac.ae, yamha@masdar.ac.ae, harafat@masdar.ac.ae).

V. H. Poghosyan is with the engineering systems and management program, Masdar Institute of Science and Technology, Abu Dhabi, 54224 UAE (e-mail: vpoghosyan@masdar.ac.ae)

$\mathrm{K}$. Torchyan is with the electrical power engineering program, Masdar Institute of Science and Technology, Abu Dhabi, 54224 UAE (e-mail: ktorchyan@masdar.ac.ae). produce steam, which is used in a Rankine Cycle Steam Turbine for electricity generation [3].

Since the HTF is thermally stable and suitable for operations up to $400^{\circ} \mathrm{C}$ [4], the temperature of the generated steam cannot exceed $380^{\circ} \mathrm{C}$. In order to increase the efficiency of the Rankine thermal cycle, CSP-natural gas hybridization can be used (Fig. 1). In this process, a booster heater is used to superheat the steam from $380^{\circ} \mathrm{C}$ to $540^{\circ} \mathrm{C}$ $[5]$.

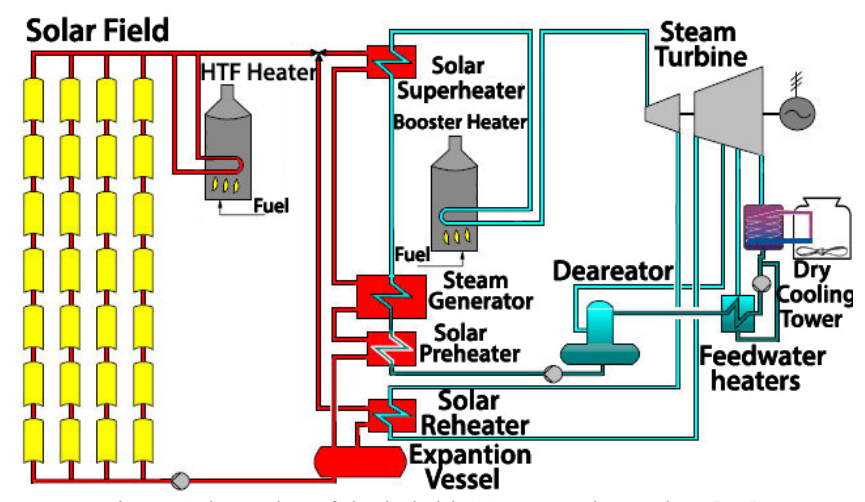

Fig. 1. Schematics of the hybrid CSP-natural gas plant [13]

The four configurations employed in CSP plants are Parabolic Trough, Solar Fresnel, Stand Alone Solar Dish, and Central Tower [3]. CSP mirrors are usually installed with a solar tracking system to ensure optimal capture of solar radiation [6]. Currently, the United States is the world leader in solar thermal power development, with $63 \%$ of the market share [7].

One disadvantage of CSP technology is that thermal energy generation is subject to daily fluctuations in solar radiation. In order to mitigate the effect of these fluctuations, the new direction is to install thermal energy storage (TES) systems. These systems store the excess thermal energy generated during the day so that it can be used at night when the sunlight energy is non-existent. Furthermore, the TES system will make the CSP system more efficient because daytime fluctuations in solar intensity can be compensated for by a regular supply of thermal energy from already stored energy [8]. In essence, the TES system acts like a battery for the CSP plant. Currently, there are only few commercial CSP plants with a TES system installed. Andasol 1,2, and 3 (in Spain), with a combined installed capacity of $150 \mathrm{MW}$, are examples of plants that employ the Molten Salt TES system for energy storage [9]. Andasol $1 \& 2$ both have storage capacities for 7.5 full load hours daily, and individual net annual output of about 150 GWhe. Another promising 
alternative to molten salt TES is Concrete TES [10]. In this system, energy is stored within a concrete mass and utilized when needed. Currently, there are no commercial plants operating with concrete TES. However, there are several experimental setups for this system, such as the WESPE [11] and the WANDA [12] projects.

In line with the Abu Dhabi 2030 vision (UAE) of achieving $7 \%$ of total energy generation from renewables by the year 2020, the government of Abu Dhabi recently commissioned the Shams-1 100MW CSP-natural gas hybridization plant. Shams-1 is the largest operational single unit CSP plant in the world [6].

This plant covers $2.5 \mathrm{~km}^{2}$ of land and utilizes over 258,000 mirrors for solar power generation using the parabolic trough system. Currently, there is no TES system in Shams-1. Therefore, the plant can only deliver electrical power generated from solar thermal energy to the grid during the day. In order to generate electrical energy at night, natural gas has to be used to heat up the HTF. However, there is a plan that future CSP plants with higher installed capacities will have TES systems that will enable them to operate up to 6000 full load hours annually [5].

In this study, we compare the environmental impacts of Concrete and Molten Salt TES systems for CSP plants, taking Shams-1 as a reference plant. This study will help in making decisions for future designs of the Shams-2 project and other commercial CSP plants. A professional LCA software, SimaPro v.7.0, was employed to conduct the impact assessment calculations.

\section{SYSTEM DESCRIPTION}

\section{A. Molten Salt TES}

In this study, a two-tank indirect molten salt TES system was considered. The thermal energy storage material is a binary salt made up of $60 \% \mathrm{NaNO}_{3}$ and $40 \% \mathrm{KNO}_{3}$ with a freezing temperature of $220^{\circ} \mathrm{C}$ [14]. The heat transfer fluid (synthetic oil/Therminol VP-1), a mixture of $73.5 \%$ diphenyl oxide and $26.5 \%$ diphenyl, is made to run through the absorber tubes of the Solar Collector Assembly (SCA), where it is heated to $400^{\circ} \mathrm{C}$. The HTF then carries the thermal energy directly to the steam generator for electricity production or into the heat exchanger where the thermal energy gained is exchanged with the cold molten salt (initial temp of $293^{\circ} \mathrm{C}$ ), to raise its temperature to $393^{\circ} \mathrm{C}$ [15]. The hot molten salt is then pumped to the hot tank for storage. At night or during cloudy conditions, a reverse action occurs as the HTF flows through the heat exchanger, carrying the stored heat of the molten salt $\left(380^{\circ} \mathrm{C}\right)$ to the steam generator for production of electricity. The cold molten salt is then pumped into the cold tank to start a new cycle (Fig. 2). In order to prevent the molten salt from freezing, heaters are installed in the cold tank to keep the temperature above $220^{\circ} \mathrm{C}$. Fig. 3 shows the cross-section of the two-tank molten salt TES system and its design parameters.

Concrete TES employs a working principle similar to that of the Molten Salt TES. Furthermore, inlet and outlet temperatures of the HTF are similar in both TES systems [16].
However, the concrete TES differs from the molten salt system in that there are no heat exchangers in the concrete TES as shown in Fig. 4. Instead, direct heat transfer occurs between the HTF and the concrete via steel pipes embedded in concrete blocks (Fig. 5).

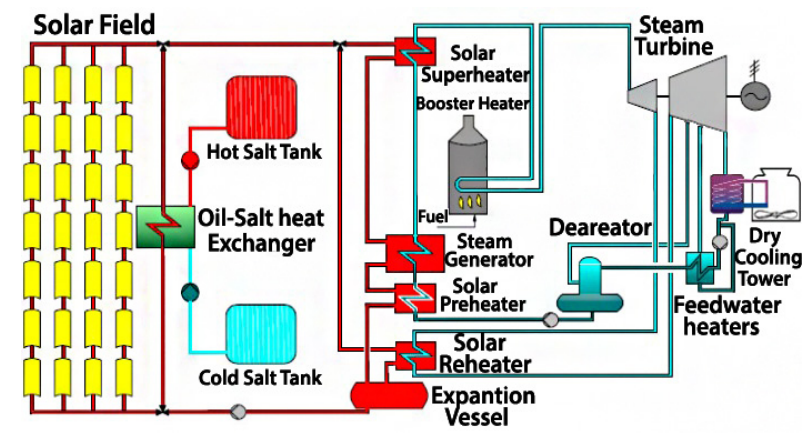

Fig. 2. Flow diagram of Molten Salt TES [13]

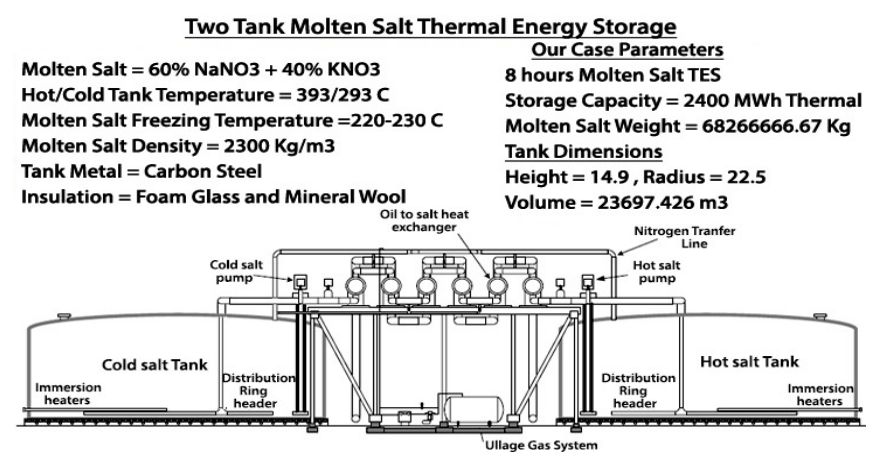

Fig. 3. Cross-section and parameters of two-tank Molten Salt TES Concrete TES [13]

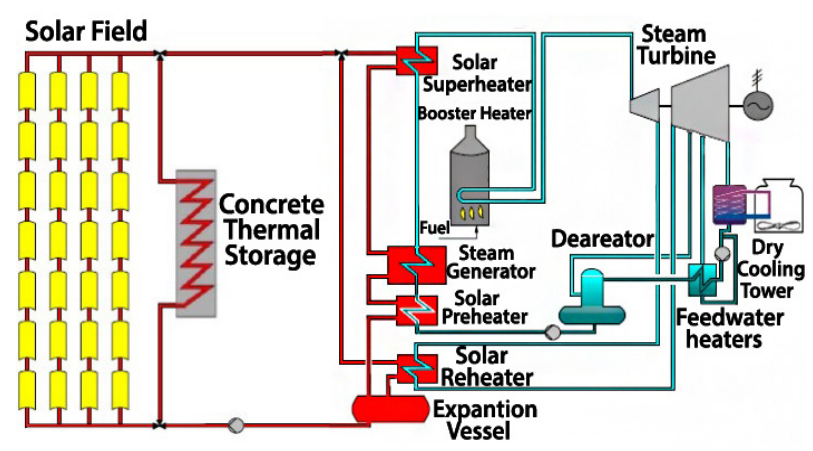

Fig. 4. Flow diagram of Concrete TES [13]

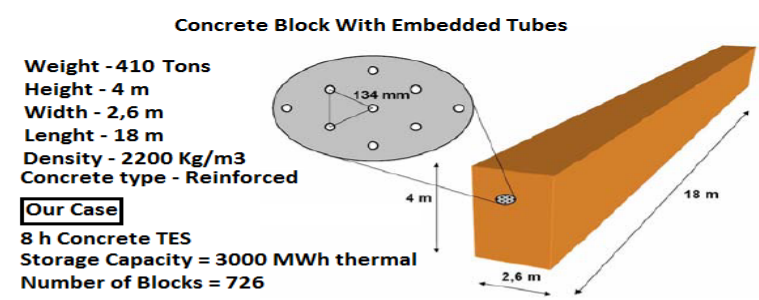
Number of Blocks $=726$

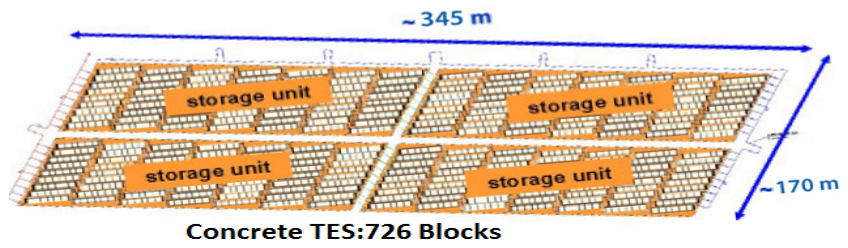

Fig. 5. Parameters of Concrete storage blocks imbedded with steel pipes [13]

Concrete TES is less efficient than molten salt TES due to high thermal losses in the system. Therefore, the concrete 
TES usually requires a larger area of solar field to compensate for these losses.

\section{Methodology}

\section{A. Goal Definition}

The goal of this Life Cycle Assessment (LCA) is to compare the environmental impacts of Molten Salt TES and Concrete TES assuming that Shams-1 CSP plant (in UAE) is retrofitted to operate with a thermal storage system. Currently, Shams-1 has no energy storage capability. Hence, a hypothetical storage system will be designed for Shams-1 by scaling-up storage specifications from other plants such as Andasol 1 [17] and WANDA [11]. The study reflects the global environmental impact of installing a storage capability for Shams 1. That is, we took into consideration the additional solar field that will be needed for a specified storage capacity without taking into account the current energy production (Table I).

TABLE I: INVENTORY FOR THE ADDITIONAL SOLAR FIELD

\begin{tabular}{|c|c|c|c|}
\hline \multicolumn{4}{|c|}{ Construction } \\
\hline & $\begin{array}{l}\text { Concrete } \\
\text { Storage }\end{array}$ & $\begin{array}{c}\text { Molten Salt } \\
\text { Storage }\end{array}$ & \\
\hline Flat Glass & 1274 & 1019.20 & $\mathrm{~kg}$ \\
\hline Copper & 3.37 & 2.69 & $\mathrm{~kg}$ \\
\hline Paint & 11.2 & 8.96 & $\mathrm{~kg}$ \\
\hline Concrete & 9616.37 & 7693.09 & $\mathrm{~kg}$ \\
\hline Reinforced Steel & 3142.92 & 2514.34 & $\mathrm{~kg}$ \\
\hline Chromium Steel & 74.99 & 59.99 & $\mathrm{~kg}$ \\
\hline Graphite & 0.039 & 0.031 & $\mathrm{~kg}$ \\
\hline $\begin{array}{l}\text { Glass Tube, } \\
\text { Borosilicate }\end{array}$ & 4.26 & 3.41 & $\mathrm{~kg}$ \\
\hline Aluminum Oxide & 0.00062 & 0.0005 & $\mathrm{~kg}$ \\
\hline $\begin{array}{l}\text { Diphenylether } 73.5 \% \\
\text { \& Phenol } 26.5 \%\end{array}$ & 413.37 & 330.70 & $\mathrm{~kg}$ \\
\hline Cast Iron & 0.119 & 0.095 & $\mathrm{~kg}$ \\
\hline Manganese & 0.119 & 0.095 & $\mathrm{~kg}$ \\
\hline Nickel & 0.009 & 0.008 & $\mathrm{~kg}$ \\
\hline Chromium & 0.009 & 0.008 & $\mathrm{~kg}$ \\
\hline Lubricating Oil & 1.724 & 1.379 & $\mathrm{~kg}$ \\
\hline Polyethylene, HDPE & 1.038 & 0.831 & $\mathrm{~kg}$ \\
\hline Area Used & 414.41 & 331.53 & $\mathrm{~m} 2$ \\
\hline \multicolumn{4}{|c|}{ Maintenance } \\
\hline Water & 139566.12 & 111652.86 & $\mathrm{~kg}$ \\
\hline Fuel, Diesel & 25.41 & 20.16 & $\mathrm{~kg}$ \\
\hline
\end{tabular}

\section{B. The Functional Unit}

Defining the functional unit (FU) for this type of system presents a challenge because the two materials being considered have different properties. Hence, in order to allow for comparison, we have designed both systems for $8 \mathrm{hrs}$ full load electricity generation (100MW), which is defined as one cycle. We defined our FU as $800 \mathrm{MWh}$ electrical energy produced per cycle (one day).

The quantities of molten salt and concrete needed for 800MWh electrical energy production have been calculated based on previous studies, assuming a linear correlation [15]. For molten salt TES, the production of 100MW for 8 hours will require the storage of $2,400 \mathrm{MWh}$ thermal energy. For concrete TES, the production of $100 \mathrm{MW}$ for 8 hours will require 3,000MWh thermal energy.

\section{System Boundary}

The system boundary of this LCA includes all activities from cradle to grave. Conceptually, this includes raw material extraction, manufacturing of system components, transportation, use, and disposal. The geographical boundary has been defined based on the location for product manufacture, use, and disposal. We have assumed that most of the system components are manufactured outside Abu Dhabi, while the use and disposal phases occur in Abu Dhabi. The disposal option chosen is landfilling, because it is the current predominant practice in Abu Dhabi. The TES has been designed for 30 years, which is also the expected life-time of Shams-1. As shown in Table II and Table III, the materials replaced within this period were taken into account based on the number of cycles for which they can be used [15].

\begin{tabular}{|c|c|c|c|c|}
\hline \multicolumn{5}{|c|}{ Concrete Storage } \\
\hline & Construction & Maintenance & Total & \\
\hline Concrete & 36766.16 & 0 & 36766.16 & $\mathrm{~kg}$ \\
\hline Graphite Foil & 4.38 & 0 & 4.38 & $\mathrm{~kg}$ \\
\hline Stainless Steel & 1302.01 & 0 & 1302.01 & $\mathrm{~kg}$ \\
\hline Mineral Wool & 493.53 & 987.06 & 1480.59 & $\mathrm{~kg}$ \\
\hline Foam Glass & 12.07 & 24.14 & 36.22 & $\mathrm{~kg}$ \\
\hline Wood & 7.97 & 0 & 7.97 & $\mathrm{~kg}$ \\
\hline $\begin{array}{l}\text { Diphenylether73. } \\
5 \% \\
\text { \& Phenol } 26.5 \%\end{array}$ & 312.76 & 312.76 & 625.51 & $\mathrm{~kg}$ \\
\hline Nitrogen & 0.05 & 0 & 0.05 & $\mathrm{~kg}$ \\
\hline Area used & 3.47 & 0 & 3.47 & $\mathrm{~m} 2$ \\
\hline Diesel Energy & 3746.5 & 169066.7 & 172813.2 & $\mathrm{MJ}$ \\
\hline Electrical Energy & 59.72 & 1756.27 & 1815.99 & $\mathrm{kWh}$ \\
\hline \multicolumn{5}{|c|}{ Molten Salt Storage } \\
\hline & Construction & Maintenance & Total & \\
\hline Concrete & 1692.18 & 0 & 1692.18 & $\mathrm{~kg}$ \\
\hline Molten Salt & 8427.98 & 0 & 8427.98 & $\mathrm{~kg}$ \\
\hline Stainless Steel & 140.61 & 0 & 140.61 & $\mathrm{~kg}$ \\
\hline Carbon Steel & 446.75 & 0 & 446.75 & $\mathrm{~kg}$ \\
\hline Mineral Wool & 34.01 & 68.02 & 102.02 & $\mathrm{~kg}$ \\
\hline Foam Glass & 10.90 & 21.79 & 32.69 & $\mathrm{~kg}$ \\
\hline Refractory Brick & 80.15 & 160.30 & 240.44 & $\mathrm{~kg}$ \\
\hline Nitrogen & 141.23 & 0 & 141.23 & $\mathrm{~kg}$ \\
\hline Area used & 0.65 & 0 & 0.65 & $\mathrm{~m} 2$ \\
\hline Diesel Energy & 3456.79 & 156800 & 160256.8 & $\mathrm{MJ}$ \\
\hline Electrical Energy & 54.87 & 4751.73 & 4806.6 & $\mathrm{kWh}$ \\
\hline
\end{tabular}

\begin{tabular}{|c|c|c|}
\hline & Expected Life (Cycles) & Equivalent factor \\
\hline Concrete & 10000 & 1 \\
\hline Graphite Foil & 10000 & 1 \\
\hline Stainless Steel & 10000 & 1 \\
\hline Mineral Wool & 3650 & 3 \\
\hline Foam Glass & 3650 & 3 \\
\hline Wood & 10000 & 1 \\
\hline $\begin{array}{l}\text { Diphenylether73.5\% } \\
\text { \& Phenol 26.5\% }\end{array}$ & 7300 & 2 \\
\hline Molten Salt & 10000 & 1 \\
\hline Carbon Steel & 10000 & 1 \\
\hline Refractory Brick & 3650 & 3 \\
\hline
\end{tabular}




\section{General Assumptions}

Since Shams-1 is a new plant, there is no accurate information on its yearly hours of operation. However, Shams-1 is expected to generate $210 \mathrm{GWhe} / \mathrm{yr}$ [5]. This is equivalent to a capacity factor of $2100 \mathrm{hr} / \mathrm{yr}$. For our analysis, we assumed that the plant operates 8 hours daily for 9 months in a year.

Some materials have been substituted because of lack of data in SimaPro as detailed below:

1) Therminol Vp-1 has been substituted with $73.5 \%$ diphenylether (w/w) and 26.5\% phenol (w/w).

2) Sodium Nitrate salt has been substituted with the theoretical chemical reaction of Nitric Acid and Nitrate Hydroxide.

\section{E. Base Case Scenario}

The defined base case has the following characteristics:

1) For all materials produced in Europe, air transportation was assumed. Sea transportation was assumed for materials produced in the United States. All local transportation is by trucks.

2) The disposal scenario for the base case was assumed to be $100 \%$ landfilling.

3) The water used for cleaning the solar field mirrors is desalinated sea-water. Since the SimaPro database does not contain desalinated water, tap water was assumed and the energy required for desalination per unit volume was added.

4) The water and the materials used in the operation and maintenance phase are decoupled in order to avoid water land disposal, set as default by SimaPro.

\section{RESULTS AND DISCUSSION}

\section{A. Base Case Scenario}

In the base case scenario, most of the impact for both TES systems came from the manufacturing and construction phase rather than the operation, maintenance, and disposal phases.

The disposal phase is credited as the largest contributor to the carcinogen and ecotoxicity categories (Fig. 6 and Fig. 7). This is because the base case disposal scenario considered is landfilling, which results in carcinogenic emissions. Most of the impacts of the manufacturing and construction phases come from air transportation of materials. As for the operation and maintenance phases, the biggest impact can be traced to cleaning of mirrors.

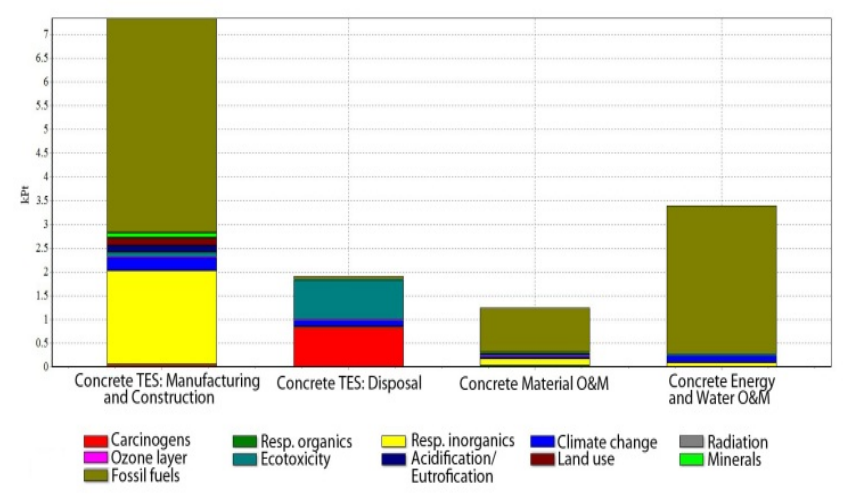

Fig. 6. Single score impact assessment of Concrete TES components

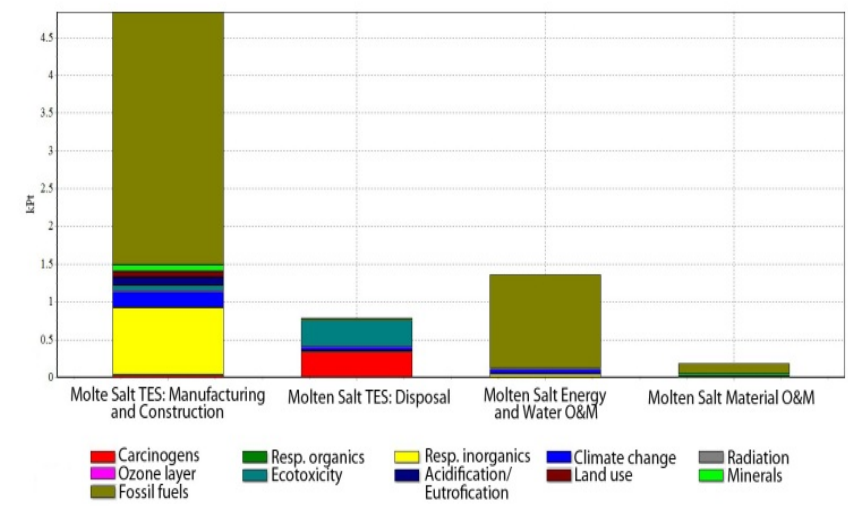

Fig. 7. Single score impact assessment of Molten Salt TES components

The base case environmental impact of the Molten Salt TES is $48.2 \%$ lower than the impact of the Concrete TES.

\section{B. Sensitivity Analysis}

In the base case scenario, the main environmental impact contributors were found to be transportation, water use and landfilling. Hence, we carried out a sensitivity analysis in which alternatives were considered for these three processes. Sensitivity analysis was carried out to test the robustness of the results obtained in the base case. The following scenarios were considered.

\section{Material Recycling}

In this scenario, we considered the recycling of steel, glass, polyethylene (PE), and polyvinylchloride (PVC) in the UAE. The energy required for dismantling the plant was considered in the analysis. However, the energy required for separating the dismantled materials was not taken into account.

\section{Water Recycling}

An on-site membrane bio-reactor (MBR) was considered for treatment of the water used in cleaning the mirrors. In this case, construction, operation, and maintenance of the MBR were considered. This almost eliminated the use of desalinated water.

\section{E. Material Transportation}

Production and transportation of materials from the local market and nearby countries was considered, instead of overseas markets.

\section{F. Combined Scenario}

A combination of all the three scenarios listed above was considered in order to model their cumulative effect.

\section{G. Sensitivity Analysis Results}

Detailed below are the changes in overall environmental impact due to the new considerations introduced in the sensitivity analysis cases.

\section{1) Material Recycling Case}

In the base case, all materials were landfilled at the end of life of the TES system. This resulted in a significant impact of carcinogens and ecotoxicity categories. In order to observe the change in environmental impact as a result of altering the disposal scenario, recycling in the UAE was taken into consideration for some materials. In this case, steel, glass, PE, and PVC were assumed to be recycled, based on the existing SimaPro recycling scenarios. 
Since only a small portion of the materials was recycled, the change in the total impact is very small and can be said to be almost negligible (Fig. 8 and Fig. 9). With respect to individual impact categories, there is only a small percentage decrease in all categories (Fig. 10 and Fig. 11).

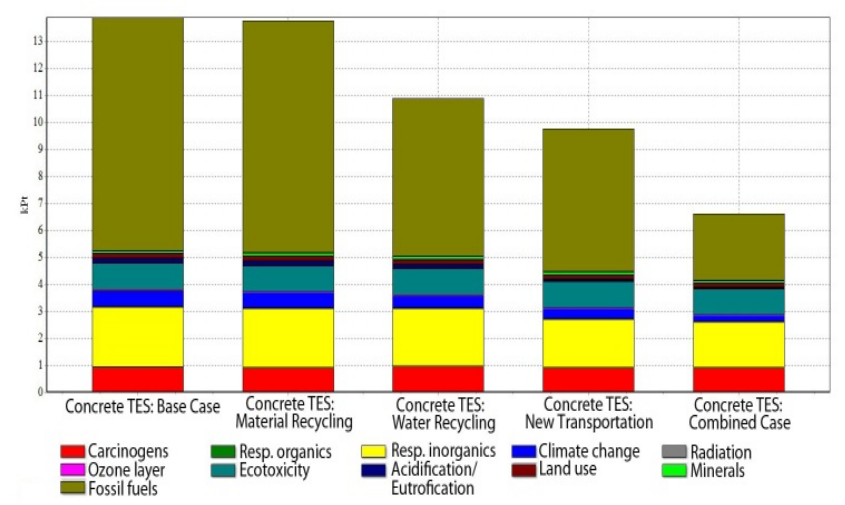

Fig. 8. Single score impact assessment comparison of all cases for Concrete TES

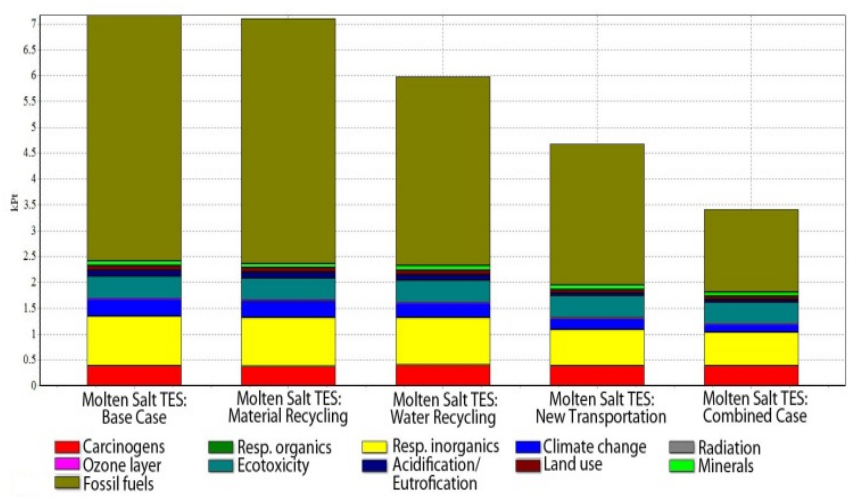

Fig. 9. Single score impact assessment comparison of all cases for Molten Salt TES

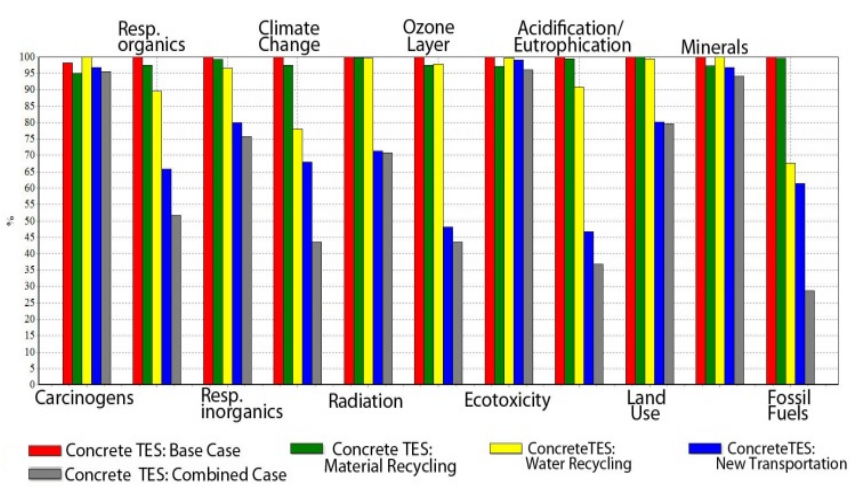

Fig. 10. Damage assessment comparison per category of all cases for Concrete TES

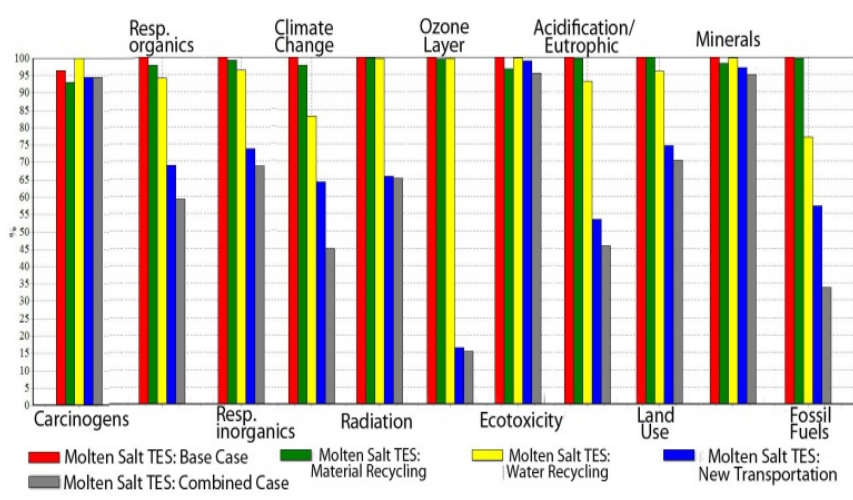

Fig. 11. Damage assessment comparison per category of all cases for Molten Salt TES
As a result of material recycling, a decrease in the mass of raw materials was observed in the inventory analysis. For example, glass recycling led to a drastic decrease in the mass of raw materials used, as every ton of glass recycled saved more than one ton of raw material needed to create new glass. The result also shows a negative flow of limestone (Fig. 12 and Fig. 13)

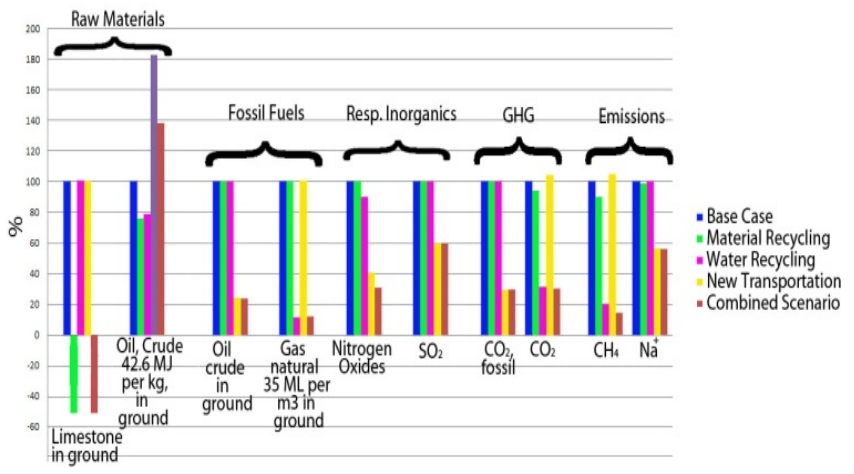

Fig. 12. Materials and emissions for Concrete TES

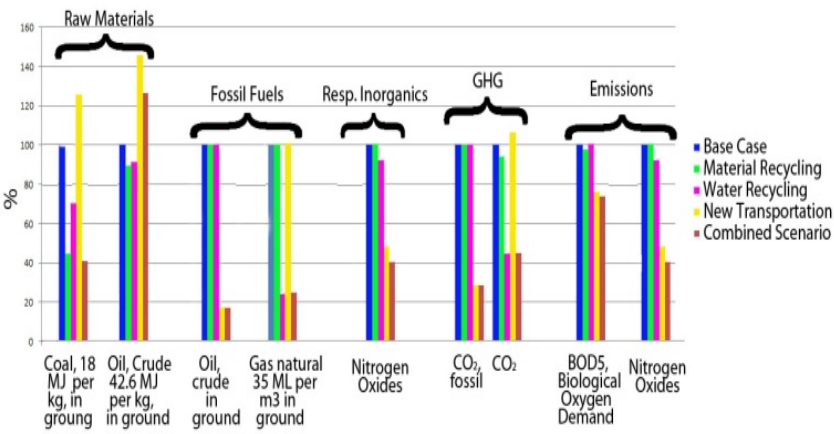

Fig. 13. Materials and emissions for Molten Salt TES

\section{2) Water Recycling Case}

In the base case, water was used for cleaning the mirrors. In order to understand the impact share of water in the system, we considered recycling the water used in cleaning the mirrors. For this reason, we designed an MBR plant to serve the CSP plant. The inventory for construction, operation and maintenance of the MBR plant, and collection of waste water are given in TABLE IV.

TABLE IV: INVENTORY FOR MBR

\begin{tabular}{|l|c|c|c|}
\hline \multicolumn{4}{|c|}{ Construction } \\
\hline & Concrete & MS & \\
\hline PVC & 0.35159 & 0.28127 & $\mathrm{~kg}$ \\
\hline PVC pipes & 0.20159 & 0.16127 & $\mathrm{~kg}$ \\
\hline Cast Iron & 0.00780 & 0.00624 & $\mathrm{~kg}$ \\
\hline Bronze & 0.00390 & 0.00312 & $\mathrm{~kg}$ \\
\hline Stainless steel & 0.05159 & 0.04127 & $\mathrm{~kg}$ \\
\hline Polypropylene & 0.00520 & 0.00416 & $\mathrm{~kg}$ \\
\hline Area used & 0.03086 & 0.02469 & $\mathrm{~m} 2$ \\
\hline \multicolumn{4}{|c|}{ Maintenance } \\
\hline Concrete & MS & \\
\hline Potassium Hydroxide & 0.03902 & 0.03121 & $\mathrm{~kg}$ \\
\hline Hydrochloride & 0.01777 & 0.01422 & $\mathrm{~kg}$ \\
\hline Electricity & 0.04270 & 0.03416 & $\mathrm{kWh}$ \\
\hline
\end{tabular}

The results show that water recycling decreases the overall impact by $21.5 \%$ and $16.6 \%$ for Concrete and Molten Salt 
TES, respectively (Fig. 8 and Fig. 9). Although the overall impact is decreased, the impact in carcinogens has increased in both cases due to the operation of the MBR plant. The categories which have experienced the largest decrease are fossil fuels consumption and climate change which decreased, respectively, by $32 \%$ and $22 \%$ for Concrete TES and by $23 \%$ and $16 \%$ for Molten Salt TES (Fig. 10 and Fig. 11). This has been achieved due to the energy saved by eliminating water desalination.

Water recycling decreased natural gas use, $\mathrm{CO}_{2}$ emission, and methane emission because in the UAE, natural gas is used to produce electricity for water desalination (Fig. 12 and Fig. 13).

In general, water recycling leads to a reduction in total impact, despite the increase it causes in carcinogens.

\section{3) New Transportation Case}

In the base case, air transport of construction materials was the main contributor to fossil fuels and climate change. Hence, in this scenario, we considered sourcing raw materials from countries nearby, such as India (TABLE V). Therefore, the energy mix of India was taken into consideration. In addition, air transport was substituted by sea transport. Road transport was left unaltered.

TABLE V: TRANSPORTATION OF THE MATERIALS

\begin{tabular}{|c|c|c|c|c|}
\hline & \multicolumn{2}{|c|}{ Base Case } & \multicolumn{2}{|c|}{ New Case } \\
\hline & Country & $\begin{array}{l}\text { Distance } \\
(\mathrm{Km})\end{array}$ & Country & \begin{tabular}{|l}
$\begin{array}{l}\text { Distance } \\
(\mathrm{Km})\end{array}$ \\
\end{tabular} \\
\hline Concrete & $\mathrm{AE}$ & 120 & $\mathrm{AE}$ & 120 \\
\hline Graphite Foil & ES & 7547 & IN & 2677 \\
\hline Stainless Steel & $\mathrm{DE}$ & 6292 & IN & 2622 \\
\hline Mineral Wool & $\mathrm{CH}$ & 6217 & IN & 2622 \\
\hline Foam Glass & $\mathrm{CZ}$ & 5769 & IN & 2622 \\
\hline Wood & $\mathrm{CH}$ & 6217 & $\mathrm{IN}$ & 3809 \\
\hline $\begin{array}{l}\text { Diphenylether73.5\% } \\
\& \text { Phenol } 26.5 \%\end{array}$ & US & 16693 & US & 16693 \\
\hline Nitrogen & $\mathrm{CH}$ & 6217 & $\mathrm{AE}$ & 280 \\
\hline Molten Salt & US & 13208 & US & 16693 \\
\hline Carbon Steel & TR & 3251 & IN & 2622 \\
\hline Refractory Brick & $\mathrm{DE}$ & 6264 & IN & 2622 \\
\hline Flat glass & $\mathrm{DE}$ & 6047.9 & $\mathrm{DE}$ & 9717 \\
\hline Copper & $\mathrm{NL}$ & 6706 & IN & 2622 \\
\hline Paint & $\mathrm{AE}$ & 280 & IN & 2622 \\
\hline Reinforced Steel & $\mathrm{DE}$ & 6292 & IN & 2622 \\
\hline Chromium Steel & $\mathrm{DE}$ & 6292 & IN & 2622 \\
\hline Graphite & $\mathrm{DE}$ & 4870 & IN & 2777 \\
\hline $\begin{array}{l}\text { Glass Tube, } \\
\text { Borosilicate }\end{array}$ & $\mathrm{DE}$ & 6292 & $\mathrm{DE}$ & 9784 \\
\hline Aluminum Oxide & $\mathrm{DE}$ & 4783 & IN & 2622 \\
\hline Cast Iron & PL & 4266 & $\mathrm{AE}$ & 280 \\
\hline Manganese & UA & 2082 & IN & 2645 \\
\hline Nickel & NL & 6706 & IN & 3012 \\
\hline Chromium & $\mathrm{BG}$ & 3335 & IN & 2622 \\
\hline Lubricating Oil & TR & 2417 & $\mathrm{AE}$ & 305 \\
\hline Polyethylene, HDPE & SE & 4827 & $\mathrm{AE}$ & 305 \\
\hline PVC & - & - & $\mathrm{AE}$ & 120 \\
\hline PVC pipes & - & - & $\mathrm{AE}$ & 120 \\
\hline Polypropylene & - & - & $\mathrm{AE}$ & 120 \\
\hline Bronze & - & - & $\mathrm{DE}$ & 6022 \\
\hline Cast Iron & - & - & $\mathrm{DE}$ & 6022 \\
\hline
\end{tabular}

Result obtained showed that the change from air transportation to sea and road transportation cut down the total impact by $28.6 \%$ and $34.7 \%$ for Concrete and Molten Salt TES respectively (Fig. 8 and Fig. 9). This is due to a decrease in fossil fuel use and the associated $\mathrm{CO}_{2}$ emission. Fig. 10 and Fig. 11 show the damage assessment per impact category for molten salt and concrete TES systems. It can be observed that the highest decrease occur in ozone layer and eutrophication categories, though these two categories account for a small shear of the total impact.

The change in transportation and energy mix caused an increase in the amount of coal and crude oil used as raw materials mainly because of the energy mix of India. On the other hand, it led to a decrease in the amount of crude oil as fossil fuel, $\mathrm{NO}_{\mathrm{x}}, \mathrm{SO}_{\mathrm{x}}, \mathrm{CO}_{2}, \mathrm{BOD}$, and Sodium ion emissions (Fig. 12 and Fig. 13).

\section{4) Combined Case}

In this analysis, we considered a combination of all the three scenarios described above.

The result shows a decrease in the total impact by $52.5 \%$ and $52.7 \%$ for Concrete and Molten Salt TES, respectively (Fig. 14). In both systems, the main contributors to the total impact are fossil fuels, climate change, ozone layer, and eutrophication (Fig. 15). Although the new transportation scenario increased the amount of coal used as raw material, in the combined case, the total amount of coal used decreased. This is due to the reduction in coal from the other two scenarios (Fig. 15). The combined scenario gives the largest decrease in the total environmental impact compared to all other scenarios.

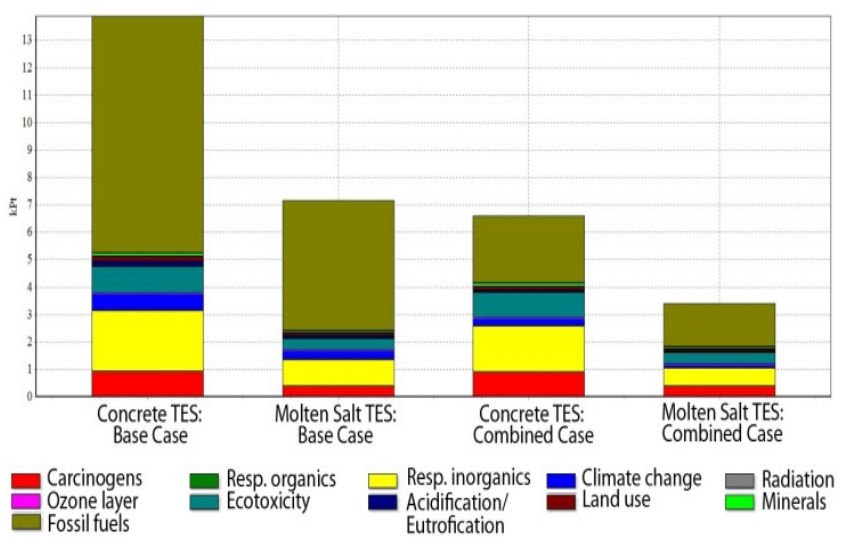

Fig. 14. Single score impact assessment comparison of base and combined cases for Molten Salt TES and Concrete TES

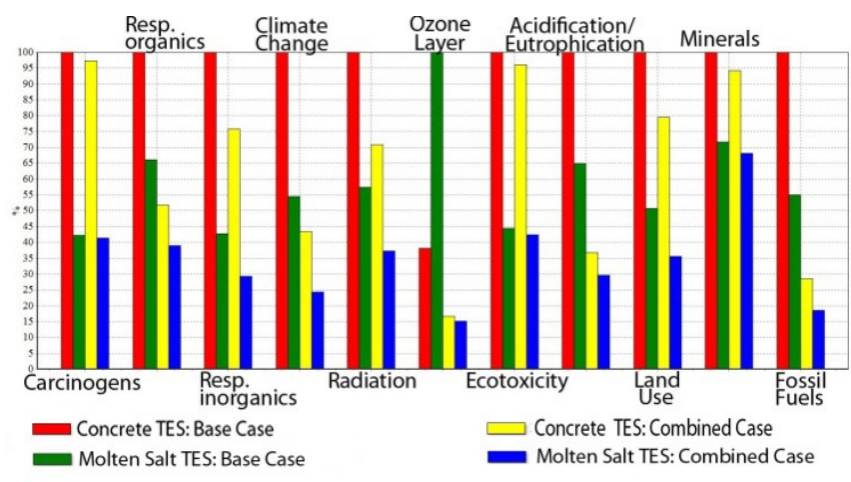

Fig. 15. Damage assessment comparison per category of base and combined cases for Concrete TES and Molten Salt TES 
In some categories, the total impact change is the average of the impact changes from all the scenarios, while in others, it can be noticed that only one of the scenarios is responsible for the total change.

\section{STUDY LIMITATIONS}

TES for CSP plants is still a new technology and there are only a few commercial CSP plant with molten salt TES, while only pilot plants that use concrete TES exist. Therefore, we had to extrapolate the inventory for Andasol and WANDA in order to design a TES for UAE's Shams-1. By doing this, we have assumed a linear correlation between the storage capacity and the quantity of construction material. However, this linear relationship does not hold in all cases.

Some of the raw materials were not found in the SimaPro database and had to be substituted with similar materials.

Recycling is still a new concept in Abu Dhabi and we were only able to project the recycling of a small portion of the material flow. Therefore, the recycling analysis did not show us the overall impact of complete material recycling.

We excluded capital goods from our inventory due to limitation of data. In similar studies reviewed, this approach has been adopted [18], [19]. However, this is a critical limitation because capital goods have a significant contribution in the manufacturing phase of renewable energy infrastructure [18], [20].

\section{CONCLUSION}

A comparative LCA was performed for two thermal energy storage systems for Shams-1 CSP plants in UAE; concrete TES and molten salt TES. Eco-Indicator 99 (EI99) was used to compare the environmental impact per 800MWhe. The results show that the concrete TES has a greater environmental impact than the molten salt TES. The biggest impact contributors in both cases were fossil fuel and respiratory inorganics. The sensitivity analysis showed that the impact can be reduced by employing a combination of transportation alternatives, on-site water recycling, and material recycling. Overall, we recommend molten salt as a more environmentally friendly thermal storage system for Shams-1.

Since the highest impact contributions for both TES systems come from the manufacturing \& construction steps, of which transport of raw materials plays a significant role, it is highly recommended to minimize transportation by looking into local markets or countries nearby. Furthermore, the sensitivity analysis showed that the impact reduction occurred in the descending order of combined case, new transport scenario, water recycling, and material recycling.

Overall, there was a $53 \%$ and $50 \%$ reduction of impact between our base case and combined scenario for the concrete TES and Molten Salt TES respectively. Therefore, we recommend the implementation of the combined scenario in order to significantly reduce the environmental impact of the TES system.

\section{ACKNOWLEDGMENT}

The authors are grateful to Abdulaziz Al Obaidli, Senior Process Engineer, Shams-1 Power Company for his comments that helped improve this manuscript.

\section{REFERENCES}

[1] P. M. Vitousek, H. A. Mooney, J. Lubchenco, and J. M. Melillo, "Human domination of Earth's ecosystems," Science, vol. 277, pp. 494-499, 1997.

[2] M. S. Common and U. Salma, "Accounting for changes in Australian carbon dioxide emissions," Energy Economics, vol. 14, pp. 217-225, 1992.

[3] D. Barlev, R. Vidu, and P. Stroeve, "Innovation in concentrated solar power," Solar Energy Materials and Solar Cells, vol. 95, pp. 2703-2725, 2011.

[4] J. E. Pacheco, S. K. Showalter, and W. J. Kolb, "Development of a molten-salt thermocline thermal storage system for parabolic trough plants," Transcations-American Society of Mechanical Engineers Jouranl of Solar Energy Engineering, vol. 124, pp. 153-159, 2002.

[5] F. L. Olaf Goebel, "Shams one 100 MW CSP plant in Abu Dhabi: update on project status" in Concentrating Solar Power \& Chemical Engineering Systems, Marrakech Morocco, 2012.

[6] S. A. Kalogirou, "Solar thermal collectors and applications," Progress in Energy and Combustion Science, vol. 30, pp. 231-295, 2004.

[7] E. F. Camacho, T. Samad, M. Garcia-Sanz, and I. Hiskens, "Control for renewable energy and smart grids," The Impact of Control Technology, Control Systems Society, pp. 69-88, 2011.

[8] M. Bosatra, F. Fazi, P. F. Lionetto, L. Travagnin, and F. W. Italiana-Corsico, "Utility-Scale PV and CSP solar power plants: Performance, impact on the territory and interaction with the grid," in Power-Gen Europe, pp. 8-10, 2010.

[9] H. Gladen, "Solar thermal power plants-firm capacity with $100 \%$ renewables," in Proc. CUEN 3rd Annual Energy Conference, Solar Millennium AG, 2009.

[10] H.-W. Yuan, C.-H. Lu, Z.-Z. Xu, Y.-R. Ni, and X.-H. Lan, "Mechanical and thermal properties of cement composite graphite for solar thermal storage materials," Solar energy, vol. 86, pp. 3227-3233, 2012.

[11] D. Laing, W.-D. Steinmann, R. Tamme, and C. Richter, "Solid media thermal storage for parabolic trough power plants," Solar energy, vol. 80, pp. 1283-1289, 2006.

[12] D. Laing, W.-D. Steinmann, M. Fiss, R. Tamme, T. Brand, and C. Bahl, "Solid media thermal ttorage development and analysis of modular storage operation concepts for parabolic trough power plants," Journal of Solar Energy Engineering, vol. 130, 2008.

[13] EPRI, "Program on technology innovation: Evaluation of concentrating solar thermal energy storage systems," Palo Alto CA: 1018464, 2009.

[14] R. I. Dunn, P. J. Hearps, and M. N. Wright, "Molten-salt power towers: Newly commercial concentrating solar storage," Proceedings of the IEEE, vol. 100, pp. 504-515, 2012.

[15] B. R. Nandi, S. Bandyopadhyay, and R. Banerjee, "Analysis of high temperature thermal energy storage for solar power plant."

[16] R. Tamme, D. Laing, and W.-D. Steinmann, "Advanced thermal energy storage technology for parabolic trough," Transcations-American Society of Mechanical Engineers Jouranl of Solar Energy Engineering, vol. 126, pp. 794-800, 2004.

[17] P. Viebahn, S. Kronshage, F. Trieb, and Y. Lechon, "Fianl report on technical data, costs, and life cycle invenotries of solar thermal power plants," DLR, CIEMAT2008.

[18] E. Oró, A. Gil, A. de Gracia, D. Boer, and L. F. Cabeza, "Comparative life cycle assessment of thermal energy storage systems for solar power plants," Renewable Energy, vol. 44, pp. 166-173, 2012.

[19] V. Piemonte, M. De Falco, P. Tarquini, and A. Giaconia, "Life cycle assessment of a high temperature molten salt concentrated solar power plant," Computer Aided Chemical Engineering, vol. 28, pp. 1063-1068, 2010.

[20] R. Frischknecht, H.-J. Althaus, C. Bauer, G. Doka, T. Heck, N. Jungbluth, D. Kellenberger, and T. Nemecek, "The environmental relevance of capital goods in life cycle assessments of products and services," International Journal of Life Cycle Assessment, vol. 12, pp. 7-17, 2007. 


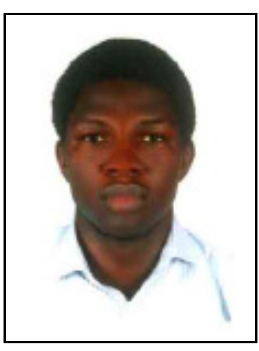

Jubilee T. Adeoye was born in Ibadan, Nigeria on March 17, 1986. He received his bachelor's degree in agricultural and environmental engineering from the University of Ibadan, Ibadan, Nigeria in 2009 $\mathrm{He}$ is currently in pursuit of his master's degree in water and environmental engineering at Masdar Institute of Science and Technology, Abu Dhabi, UAE.

He worked as an intern at Zenith Bank PLC, Lagos, Nigeria and at several research institutes including the International Institute of Tropical Agriculture, Ibadan, Nigeria. He is currently a Research Assistant in the department of water and environmental engineering at Masdar Institute of Science and Technology, Abu Dhabi, UAE. His research involves mitigation of salt deposition for seawater irrigation of halophytes

Mr. Adeoye is a certified associate in project management (CAPM) and a member of the Nigerian Society of Engineers (NSE).

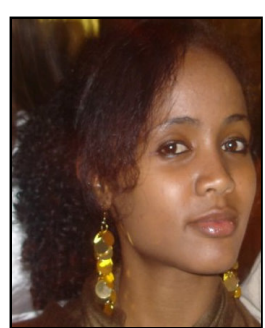

Yamrot M. Amha was born in Addis Ababa, Ethiopia on November 26, 1987. She completed her Bachelors of Science degree in environmental and occupational health from California State University, Northridge, USA, in 2011. Currently, Yamrot is pursuing her Master's Degree in wate and environmental engineering at Masdar Institute of Science and Technology, Abu Dhabi, UAE.

She worked as an intern at Ventura County Environmental Health Agency. She also worked as a Program Coordinator at Clinton Foundation in Addis Ababa Ethiopia. After earning her first degree, she worked at Quest Diagnostics as a Laboratory Associate II. Her current research work is on Quantitative Microbial Risk Assessment of treated wastewater for irrigation use in Abu Dhabi. She works as a Graduate Research Assistant in the Bio-Energy and Environmental Lab (BEEL) at Masdar Institute.

Ms. Amha is a member of The National Society of Collegiate Scholar, Women Environmental Council and National Society of Black Engineers (NSBE).

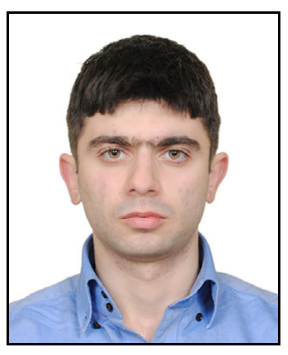

Vahan H. Poghosyan was born in Yerevan, Armenia on September 29, 1991. He received BEng degree in power engineering from State Engineering University of Armenia, Yerevan, Armenia, in 2012. He is on his way to obtain his master's degree in engineering systems and management from Masdar Institute of Science and Technology, Abu Dhabi, UAE. His major field of study is optimal design of thermal energy storage systems for concentrated solar power plants.
$\mathrm{He}$ is a research assistant in the department of engineering systems and management at the Masdar Institute of Science and Technology, Abu Dhabi, UAE. His research involves two tank indirect molten salt Thermal Energy Storage System design for parabolic trough power plants.

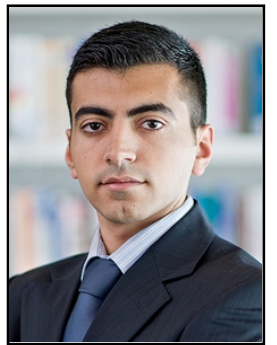

Khachatur Torchyan was born in Yerevan, Armenia on January 1, 1990. He received BEng and MSc degrees in electrical engineering from State Engineering University of Armenia, Yerevan, Armenia, in 2009 and 2011 respectively. He is on his way to obtain MSc degree in electrical power engineering from Masdar Institute of Science and Technology, Abu Dhabi, UAE. His major field of study is renewable energy generations interconnection to the grid at transmission level.

$\mathrm{He}$ is a research assistant in the department of electrical power engineering at the Masdar Institute of Science and Technology, Abu Dhabi, UAE. His research involves power system modeling, voltage control strategies and coordinated control.

Mr. Torchyan is an IEEE PES student member.

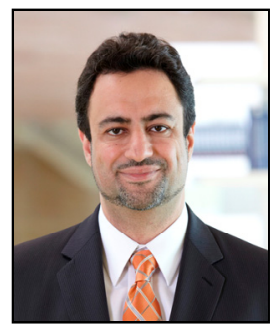

Hassan A. Arafat obtained his B.Sc. in Chemical Engineering from the University of Jordan, Amman, Jordan in 1996 and his Ph.D. in Chemical engineering from the University of Cincinnati, Cincinnati, USA in 2000. He worked at Argonne National Laboratory (ANL) Illinois, USA as a researcher and project manager for the United States Department of Energy (DOE) between 2000 and 2003. Afterwards, he served as a faculty member at the Chemical Engineering Department at An-Najah University, Nablus, Palestine, and as the director of the "Water Technologies Research Unit" of the department between 2003 and 2010.

In 2010, he joined Massachusetts Institute of Technology as a visiting scholar for six months, after which he moved to Abu Dhabi, UAE, where he is now employed as an associate professor in the water and environmental engineering program at Masdar Institute of Science and Technology, Abu Dhabi, UAE. Dr. Arafat has co-authored more than 100 peer-reviewed journal publications, conference papers, and official technical reports. 